\title{
Simulação numérica de pilares tubulares de aço reforçados com PRFC submetidos à compressão
}

\author{
Lucas Augusto Milani Lopes ${ }^{1}$ e Ronaldo Rigobello ${ }^{2 *}$ \\ ${ }^{1}$ Programa de Pós-graduação em Engenharia Civil, Universidade Estadual de \\ Maringá, lucasmilanilopes@gmail.com \\ 2 Universidade Tecnológica Federal do Paraná - Campus Campo Mourão, \\ rigobello@utfpr.edu.br
}

\section{Numerical modeling of steel tubular columns strengthened with CFRP under axial compression}

\begin{abstract}
Resumo
$\mathrm{O}$ uso dos $\mathrm{PRFC}^{1}$ para a recuperação e reforço de estruturas de concreto é uma técnica consagrada e já difundida. Porém, a sua aplicação em estruturas de aço ainda é bastante restrita, principalmente no Brasil, apesar de se apresentar como uma técnica viável e promissora. Em relação à solicitação de compressão, os elementos usuais na prática geralmente falham por instabilidade, e a presença do reforço com PRFC pode retardar ou mesmo eliminar tais instabilidades, aumentando sua capacidade resistente. Nesse contexto, foi desenvolvida uma estratégia numérica capaz de simular o comportamento estrutural de pilares tubulares quadrados de aço, reforçados com PRFC e solicitados á compressão centrada. A eficiência da estratégia numérica desenvolvida foi verificada por meio da validação dos resultados obtidos por comparação com resultados experimentais presentes na literatura.
\end{abstract}

Palavras-chave: Reforço de estruturas de aço com PRFC, pilares tubulares de aço, simulações numéricas.

\begin{abstract}
The use of CFRP for the recovery and strengthening of concrete structures is a well-established and widespread technique. However, its application in steel structures is still very restricted, mainly in Brazil, despite presenting itself as a viable and promising technique. In relation to the compression solicitation, the usual elements in practice generally fail due to instability, and the presence of the reinforcement with CFRP can delay or even eliminate such instabilities, increasing its resistant capacity. In this context, a numerical strategy was developed for simulating the structural behavior of square steel tubular columns, strengthened with CFRP under axial compression load. The efficiency of the numerical strategy developed was verified through the validation of the results obtained with the simulations by comparison with experimental results presents in the literature.
\end{abstract}

Keywords: Strengthening of steel structures with CFRP, steel tubular columns, numerical simulations.

\footnotetext{
${ }^{1}$ PRFC - Polímero Reforçado com Fibra de Carbono
} 


\section{Introdução}

Ao longo da vida útil das estruturas de aço é comum a necessidade de reparo ou reforço das mesmas, seja devido a ocorrência de deterioração em função da idade da estrutura e estado de corrosão das peças ou mesmo devido à alteração do seu uso, em que as novas cargas atuantes venham a exceder as cargas previstas em projeto.

De acordo com Zhao e Zhang (2007), o método convencional de reparo ou reforço de estruturas de aço consiste no corte e substituição parcial de chapas constituintes do elemento ou na inserção de chapas externas ao perfil, sendo essas chapas geralmente volumosas, pesadas, de difícil manipulação e propensas a corrosão e a fadiga. Neste contexto, o reforço de estruturas de aço com polímeros reforçados com fibra se mostra uma solução de grande potencial.

Ao longo das últimas duas décadas, os $\mathrm{PRF}^{2}$ têm ganho gradual aceitação em aplicações de engenharia estrutural devido às suas vantagens ímpares, dentre as quais se destacam a sua elevada relação resistência-peso e excelente resistência a corrosão. O uso dos PRF para a recuperação e reforço de estruturas de concreto se mostra uma técnica consagrada e já difundida, porém, a sua aplicação em estruturas de aço ainda é bastante restrita, principalmente no Brasil. Em outros países, como o Reino Unido, Estados Unidos, Itália e Japão, já existem manuais de projeto referentes ao reforço de estruturas de aço com PRF. A primeira aplicação de PRF para o reforço de estruturas metálicas foi na ponte de Tickford no Reino Unido (LANE e WARD, 2000).

Tawfik e Karunasena (2010) afirmam que, as principais propriedades dos PRFC dependem do tipo e orientação das fibras de carbono (direção transversal ou longitudinal), do tipo e porcentagem do material resinoso e das condições de cura. Assim, existem diferentes tipos de PRFC com diferentes propriedades.

O reforço de pilares tubulares de aço circulares ou retangulares, com PRFC, basicamente pode ser efetuado de duas maneiras: a primeira com as fibras orientadas transversalmente em relação ao eixo longitudinal do pilar e uma segunda com as fibras orientadas paralelas ao eixo. Desta maneira, o reforço pode ser efetuado através da composição de diferentes configurações das camadas (ZHAO, 2014).

\footnotetext{
${ }^{2}$ PRF - Polímeros Reforçados com Fibra
} 
Para pilares curtos ou não esbeltos, Shaat e Fam (2006) reportam que a disposição de camadas laminados de PRFC transversalmente em relação ao eixo longitudinal do pilar se mostrou eficaz para o reforço de pilares submetidos à esforços de compressão. No entanto, para pilares medianamente esbeltos ou esbeltos a disposição de camadas de laminados de PRFC orientadas no mesmo sentido do eixo do elemento se mostrou mais eficaz no reforço à compressão, ou seja, apresentou maiores ganhos de resistência quando comparado aos casos de disposição das camadas de laminados na direção transversal ao eixo do pilar.

$\mathrm{Na}$ investigação e difusão de novas tecnologias, há tempos atrás, as análises experimentais dominavam o cenário das pesquisas cientificas, visto que, as análises numéricas possuíam limitações de software e principalmente hardware para processamento. Atualmente, com o avanço da capacidade de processamento dos computadores e a possibilidade de se obter resultados de maneira rápida e eficaz, com custos bem inferiores às análises experimentais, a investigação numérica utilizando o $\mathrm{MEF}^{3}$ vem se tornando cada vez mais comum.

Nesse contexto, são apresentados os principais critérios e particularidades da estratégia de modelagem numérica desenvolvida com o auxílio do software ANSYS ${ }^{\circledR}$ Academic Research Mechanical, Release 18.1 (ANSYS Inc., 2017), devidamente calibrada com base em resultados experimentais existentes na literatura. Por fim, há de se constatar que essa estratégia é uma ferramenta poderosa para investigação do comportamento estrutural de pilares de aço tubulares reforçados com PRFC.

\section{Aspectos gerais da estratégia de modelagem numérica}

A estratégia numérica foi desenvolvida para aplicação via interface Mechanical APDL do ANSYS ${ }^{\circledR}$, seguindo a sequência do fluxograma apresentada na figura 1. APDL é um acrônimo para ANSYS Parametric Design Language, uma poderosa linguagem de script que permite ao usuário parametrizar o modelo e automatizar tarefas comuns, típicas de análises paramétricas.

\footnotetext{
${ }^{3}$ MEF - Método dos Elementos Finitos
} 
Visando um melhor desempenho, aproximações geométricas e mecânicas foram realizadas. As seções $\mathrm{SHS}^{4}$, as quais possuem vértices arredondados, foram aproximadas a vértices angulosos, formando assim um octógono. Tal aproximação não interfere na resposta numérica global e possibilita uma maior eficiência do modelo em termos de processamento, evitando refinamentos de malha consideráveis nas proximidades dos vértices ou mesmo a utilização de elementos finitos de ordem superior no modelo. Em relação ao reforço de PRFC, as camadas são modeladas como uma única camada de mesma equivalência mecânica que o conjunto original. Tais aproximações são apresentadas na Figura 2.

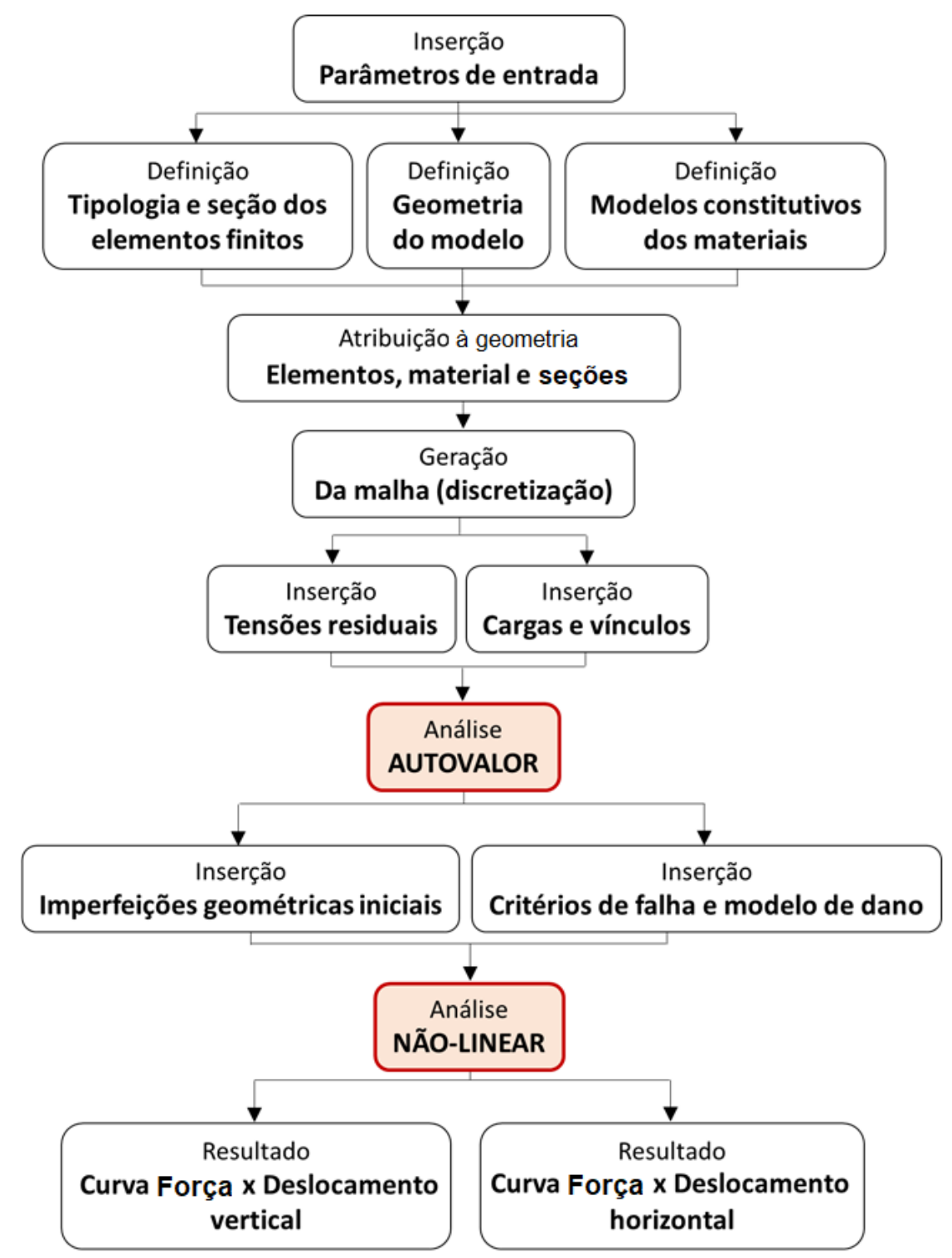

Figura 1 - Fluxograma apresentando o resumo da estratégia numérica.

\footnotetext{
${ }^{4}$ SHS - Square Hollow Section (Seção Tubular Quadrada)
} 

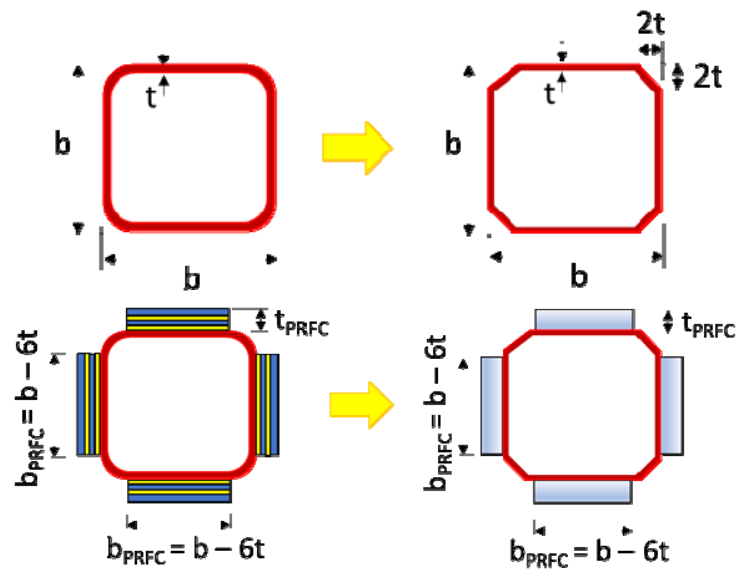

Figura 2 - Simplificações geométricas e mecânicas.

O pilar e o reforço em PRFC foram simulados com elementos finitos do tipo casca. Nas extremidades dos pilares são simuladas chapas, denominadas por chapas de base e de topo, respectivamente, também com elementos do tipo casca. Estas possuem rigidez significativa, visando representar de forma real os ensaios experimentais. A Figura 3 ilustra o exposto.

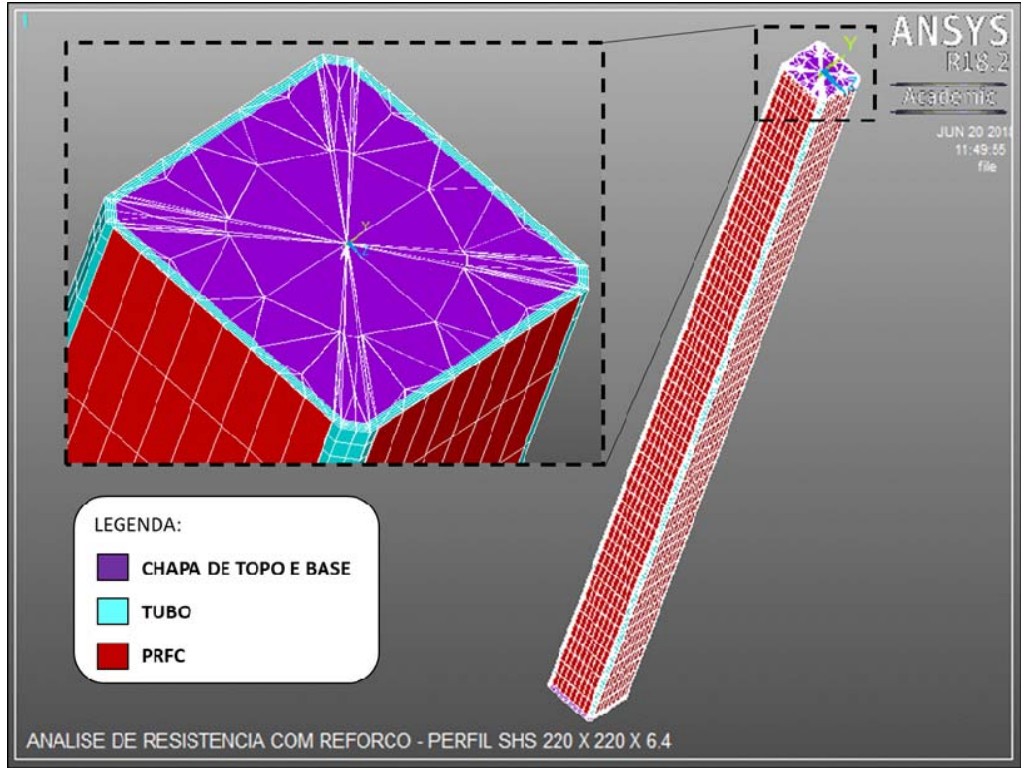

Figura 3 - Modelo tridimensional com elementos do tipo casca.

Como estratégia de modelagem, foi utilizado o comando "SECOFFSET" para a localização dos nós do elemento finito na seção transversal do mesmo. Como padrão, os nós são posicionados ao longo da superfície média do elemento, no caso de elementos de casca. Para esta pesquisa estes foram transladados para uma das superfícies externas do elemento, sejam coincidentes ser comuns tanto aos elementos 
que representam os tubos de aço quanto para o reforço em uma situação de interação total. Essa estratégia é apresentada na Figura 4.

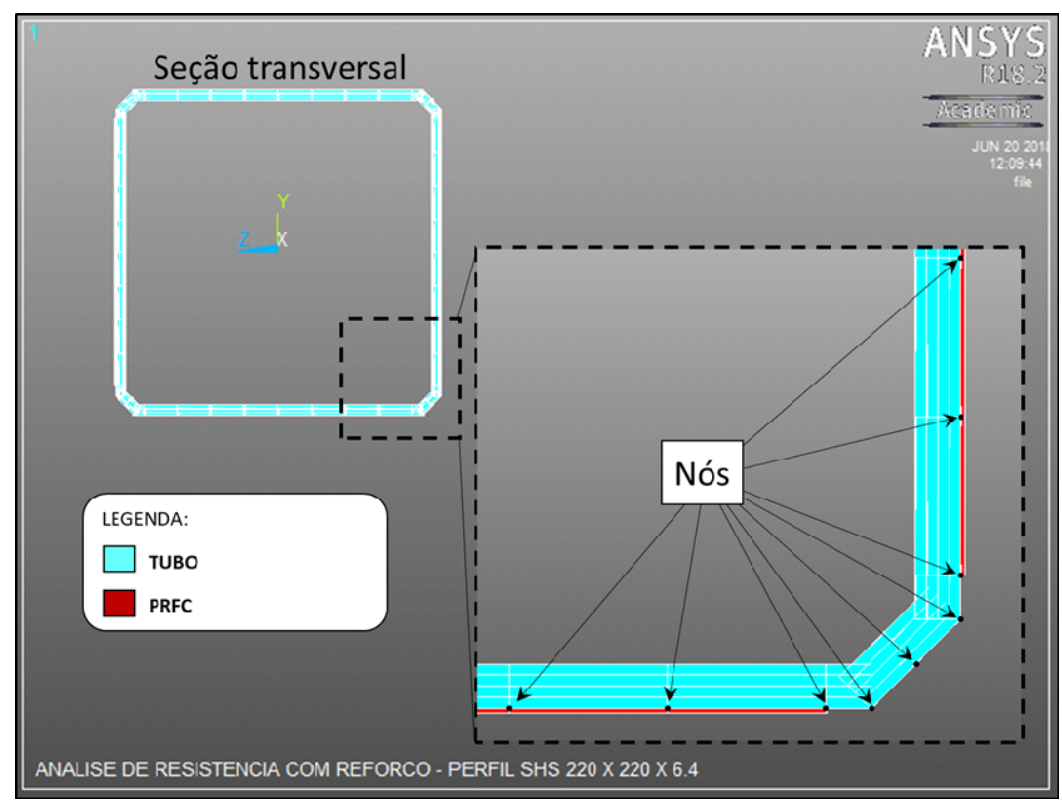

Figura 4 - Utilização do comando "SECOFFSET" para a composição do modelo.

Segundo Pereira (2013), a biblioteca do software ANSYS ${ }^{\circledR}$ dispõe de uma grande variedade de elementos e a escolha do elemento deve ser efetuada de acordo com as premissas relativas à geometria, materiais e características intrínsecas do elemento, buscando uma resposta coerente e satisfatória.

Nesta simulação, o perfil tubular, as chapas de extremidade e o PRFC foram simulados através do elemento de área SHELL181. Consiste em um elemento de casca triangular ou quadrilátero, composto por três ou quatro nós, respectivamente, com seis graus de liberdade por nó (três translações e três rotações) e é indicado para a análise de estruturas cujas as paredes constituintes do elemento sejam finas ou medianamente espessas. Admite-se ainda a realização de análises lineares ou não-lineares com grandes deformações e rotações.

Além disso, o SHELL181 permite simular também o comportamento de membrana, ou seja, os graus de liberdade de cada nó são reduzidos a apenas três (três translações), sendo este comportamento adotado para o PRFC. Outras características a serem mencionadas é a possibilidade de inserção de múltiplas camadas ao longo da sua espessura, podendo impor diferentes comportamentos e espessuras para cada 
camada, além de permitir a introdução de um estado inicial de tensões, utilizado na simulação de tensões residuais. A Figura 5, apresentada a seguir, ilustra o elemento mencionado.

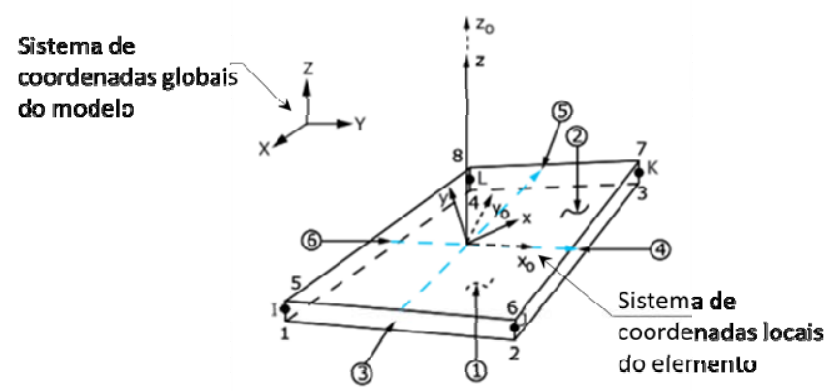

Figura 5 - Elemento finito bidimensional SHELL181. Fonte: ANSYS Inc. (2017).

O comportamento do aço dos perfis tubulares, foi idealizado como elastoplástico perfeito, bilinear, tendo o segundo trecho pequena inclinação apenas para evitar problemas de convergência. Um diagrama bilinear descreve o modelo constitutivo do material com base no módulo de elasticidade longitudinal (E), a tensão de escoamento do aço $\left(f_{y}\right)$ e um módulo plástico $\left(E_{t}\right)$. A critério de análise, o módulo de elasticidade do regime plástico $\left(E_{t}\right)$, foi considerado como sendo 0,5 por cento do módulo de elasticidade (E), de forma análoga ao efetuado por Shaat (2007).

Os PRFC possuem comportamento elástico linear até a ruptura, sendo a ruptura caracterizada como frágil. O modelo reológico para o PRFC foi considerado como elástico linear e a falha foi acoplada através de um modelo de dano, abordado adiante. Como parâmetros básicos para o modelo constitutivo do PRFC tem-se o módulo de elasticidade $(E)$, a tensão de ruptura $\left(f_{u}\right)$ e a deformação última de ruptura $\left(\varepsilon_{u}\right)$. Ambos os modelos, do aço e do PRFC são apresentados na Figura 6.

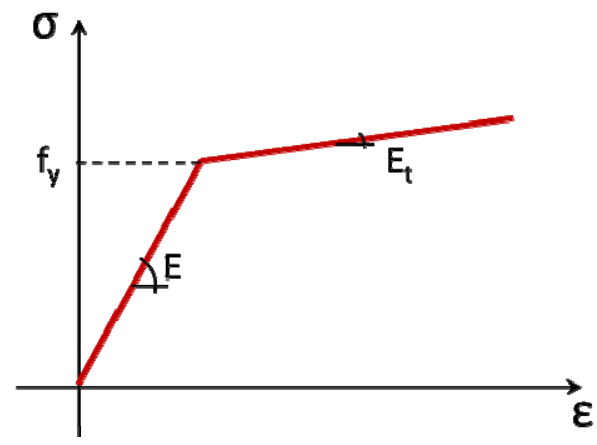

(a)

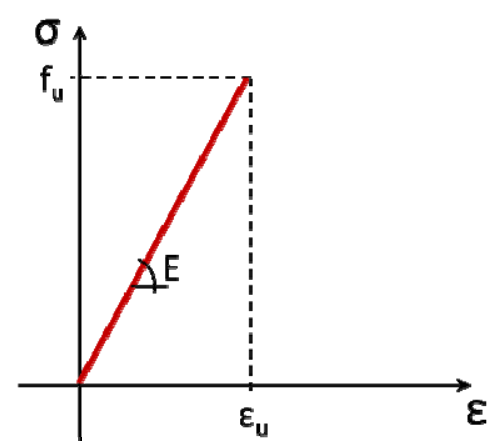

(b)

Figura 6 - (a) Modelo bilinear com patamar de enrijecimento utilizado para o aço e (b) Modelo elástico linear utilizado para o PRFC. 
Como estratégia de modelagem, para o comportamento na interface aço e PRFC, não se considerou a falha devido ao descolamento da fibra, ou seja, a interação entre o PRFC e o aço é plena. Esse aspecto foi possível através do acoplamento dos nós, ao longo dos elementos na interface entre o tubo e o PRFC, tornando compatível os seus deslocamentos.

No modelo, os pilares foram considerados como biapoiados. Para tanto, o nó central da chapa de base teve as translações ao longo dos eixos $x, y$ e $z$ restringidas e o nó central da chapa de topo as translações em y e $z$, visto que, o eixo longitudinal do elemento é o $x$. Para evitar a ocorrência de uma inconsistência numérica e a impossibilidade de resolução do sistema, o nó central da chapa de base, teve a sua rotação em torno do eixo $x$ restrita.

Para evidenciar o modo de falha por instabilidade global em torno do eixo $z$, sendo esta uma premissa necessária, o nó central da chapa de base teve a rotação em torno do eixo y também restrita.

Os carregamentos foram aplicados no nó central da chapa de topo e se subdividiram em duas etapas. A primeira etapa consistiu na aplicação de uma carga unitária, utilizada para o cálculo do primeiro modo de instabilidade do elemento, através de uma análise de autovalor. Isso tem por objetivo possibilitar a geração da geometria deformada do elemento estrutural para consideração das imperfeições geométricas iniciais. A segunda etapa consistiu em aplicar um deslocamento prescrito, subdivido em partes, denominados "substeps", também no nó central da chapa de topo. Então, efetuou-se uma análise não linear de convergência de todos os "substeps" para a geração dos resultados.

Em 1807, Young propôs que as imperfeições iniciais globais do eixo de barras, tivessem geometria semelhante a uma senóide. Obviamente que, essa proposição é aproximada, mas muito bem aceita na prática. Esta suposição de Young foi tão importante para se prever as imperfeições que a mesma foi utilizada como base para as curvas de resistência americanas e europeias (CHODRAIU, 2006). 
As imperfeições geométricas iniciais foram consideradas partindo-se da configuração deformada da estrutura em função do primeiro modo de instabilidade, definido através da análise de autovalor. No ANSYS ${ }^{\circledR}$, este fato é possível através do comando "UPGEOM". Este comando, introduz na configuração indeformada do elemento deslocamentos pré-definidos em análise prévia, sendo estes multiplicados por um fator de escala. O fator de escala é definido em função do valor da imperfeição geométrica a ser inserida, para que ao final essa imperfeição inicial seja equivalente àquela mensurada experimentalmente.

Nessa estratégia, as tensões residuais foram inseridas como sendo um estado inicial de tensões, auto equilibrado. Para tanto, as chapas constituintes dos perfis tubulares foram subdivididas em quatro camadas ao longo da sua espessura. Nas camadas externas, foram inseridas as maiores intensidades das tensões residuais, sendo, na camada externa uma tensão de tração e na interna de compressão. Nas duas camadas intermediárias, foram inseridas tensões com $50 \%$ da intensidade máxima, seguindo a mesma lógica das camadas externas. A Figura 7, ilustra a distribuição de tensões residuais descrita.

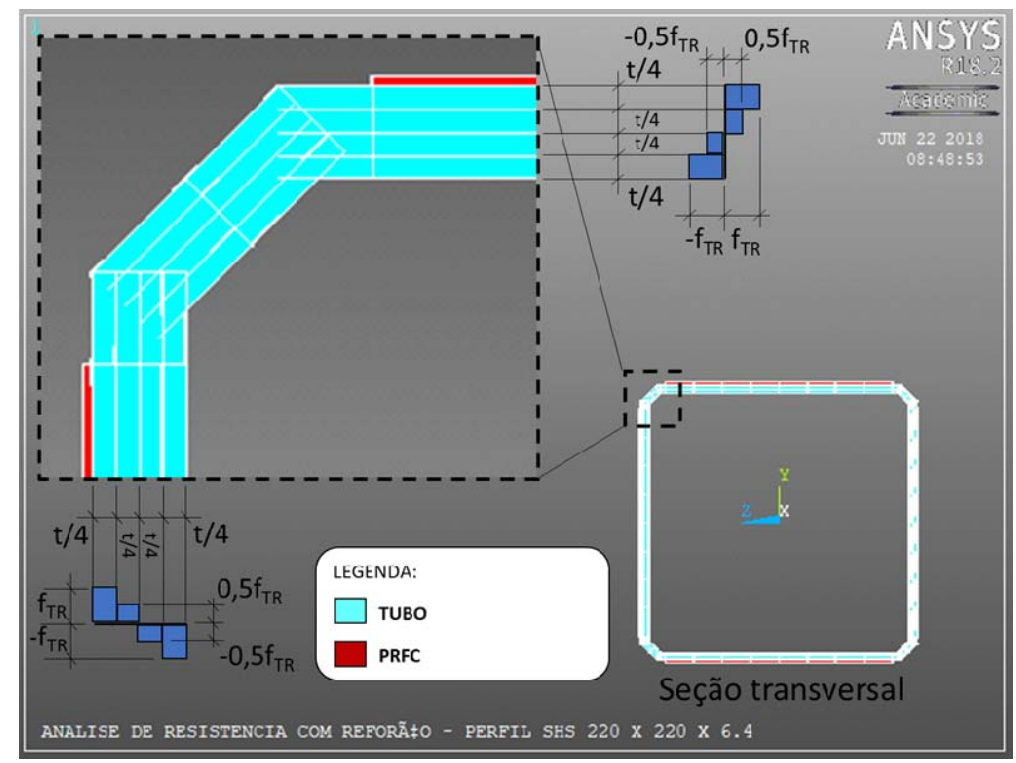

Figura 7 - Inserção de tensões residuais nas paredes dos perfis tubulares.

Essa maneira simplificada de se introduzir as tensões residuais ao modelo também foi utilizada por Shaat (2007), que ainda afirma que as tensões residuais podem acarretar em um pequeno ganho ou perda de resistência para elementos medianamente esbeltos e esbeltos, da ordem de 2 a $6 \%$. 
Experimentalmente, para pilares reforçados com PRFC, ocorre um complexo modo de falha, o qual envolve um descolamento localizado associado a instabilidade local e esmagamento da fibra, imediatamente após a ocorrência de flambagem global. Quando o perfil tubular possibilita um grande comprimento de ancoragem do PRFC, ou seja, para elementos longos, a falha ocorre essencialmente por esmagamento do PRFC (SHAAT, 2007).

Shaat (2007), em sua campanha experimental, mediu as deformações do PRFC ao longo dos seus experimentos e afirma que, para elementos relativamente curtos, a deformação última à compressão do PRFC se mostra inferior à de elementos longos e conclui que as deformações últimas aumentam com o aumento da esbeltez do elemento. A partir deste comportamento, foi desenvolvido uma expressão bilinear, que configura a deformação última de compressão do $\operatorname{PRFC}\left(\varepsilon_{\mathrm{uc}}\right)$, que se mostra uma função do índice de esbeltez do elemento e correlata à deformação última de tração $\left(\varepsilon_{\mathrm{ut}}\right)$, medida experimentalmente. A regra desenvolvida e acoplada ao modelo é expressa pelas equações a seguir:

$$
\begin{aligned}
& \left(\frac{s_{w a}}{s_{w t}}\right)=7.8 \times 10^{-8} \frac{k L}{r^{r}} \quad \text { para } \quad \frac{k E}{r^{r}} \leq 7 \epsilon \\
& \left(\frac{a_{w a}}{s_{w t}}\right)=0.59 \quad \quad \text { para } \quad \frac{k E}{r^{r}}>76
\end{aligned}
$$

Essa lógica foi inserida no modelo numérico, sendo definida como critério de falha. Os elementos simulados podem ou não atingir a falha. Quando atingido o critério de falha, é então disparado o modelo de dano, sendo definido como uma redução da rigidez dos elementos de reforço.

A estratégia de solução utiliza o método de "comprimento de arco". Em casos lineares simples, a análise de autovalores é suficiente, porém em situações em que existe a necessidade de se considerar a não linearidade geométrica e de material, instabilidade e grandes deformações, a análise de convergência interativa pelo método do comprimento de arco se mostra eficiente (DEVI, 2016).

Como padrão, o ANSYS ${ }^{\circledR}$ utiliza o método Newton-Raphson para efetuar análises não lineares. No caso específico, os modelos foram analisados efetuando-se acréscimo de 
deslocamentos ao invés de força, sendo a aplicação do deslocamento total subdivida em etapas (substeps), junto com o método do comprimento de arco, afim de se tentar descrever com maior precisão o ramo pós pico da curva força $\mathrm{x}$ deslocamento.

\section{Simulações, calibração e validação dos resultados obtidos}

Afim de validar os resultados obtidos, inicialmente são elaborados modelos numéricos sem reforço e os resultados são comparados a resultados experimentais obtidos de Shaat (2007).

Na sequência são avaliados os modelos contendo o reforço. Para tanto, foi introduzido o critério de falha, conforme descrito anteriormente, sendo que, a partir da sua ocorrência, os PRFC sofrem uma perda das suas propriedades mecânicas (rigidez). Nas situações com reforço, diferentes fatores de dano foram testados, sendo este definido como um fator redutor da rigidez do elemento. Caso o fator seja imposto igual a 0 , não ocorre nenhuma redução e caso seja igual a 1 a redução é total. Valores intermediários entre 0 e 1 , reduzem proporcionalmente a rigidez. Dessa forma, são apresentados resultados obtidos através de vários fatores, afim de facilitar a definição do fator que venha melhor se ajustar aos resultados experimentais.

A calibração e validação de resultados, para elementos reforçados ou não, foi efetuada por comparação direta à resultados experimentais obtidos na pesquisa de Shaat (2007). Dentro dessa pesquisa, referente ao comportamento à compressão, foram ensaiados cinquenta pilares de seções SHS, com comprimento variando de 175 a 2380 mm, implicando em índices de esbeltez de 4 a 93, com o intuito de se avaliar a influência de parâmetros como o número de camadas e tipologia do PRFC, orientação da fibra e esbeltez no comportamento do elemento.

Shaat (2007), conforme citado anteriormente, menciona que o reforço com as fibras dispostas no sentido longitudinal se mostra mais eficiente no caso de elementos medianamente esbeltos ou esbeltos, objeto do presente estudo.

Um resumo da campanha experimental, para pilares longos, efetuada para avaliar o comportamento de pilares reforçados com PRFC e PRFV 5 segundo esse autor é apresentado na tabela 1. Nessa tabela, "G" significa utilização de PRFV para a camada

\footnotetext{
${ }^{5}$ PRFV - Polímero Reforçado com Fibra de Vidro
} 
de base, "L" se refere à disposição das fibras no sentido longitudinal, paralela ao eixo do elemento. C3 é a designação dada ao PRFC de nome comercial Dialead F637400 (Mitsubishi Chemical, Chesapeake, Virginia) e C5 é a designação dada ao PRFC de nome comercial Sika CarboDur H514.

Tabela 1 - Resumo da campanha experimental de Shaat (2007) para pilares longos.

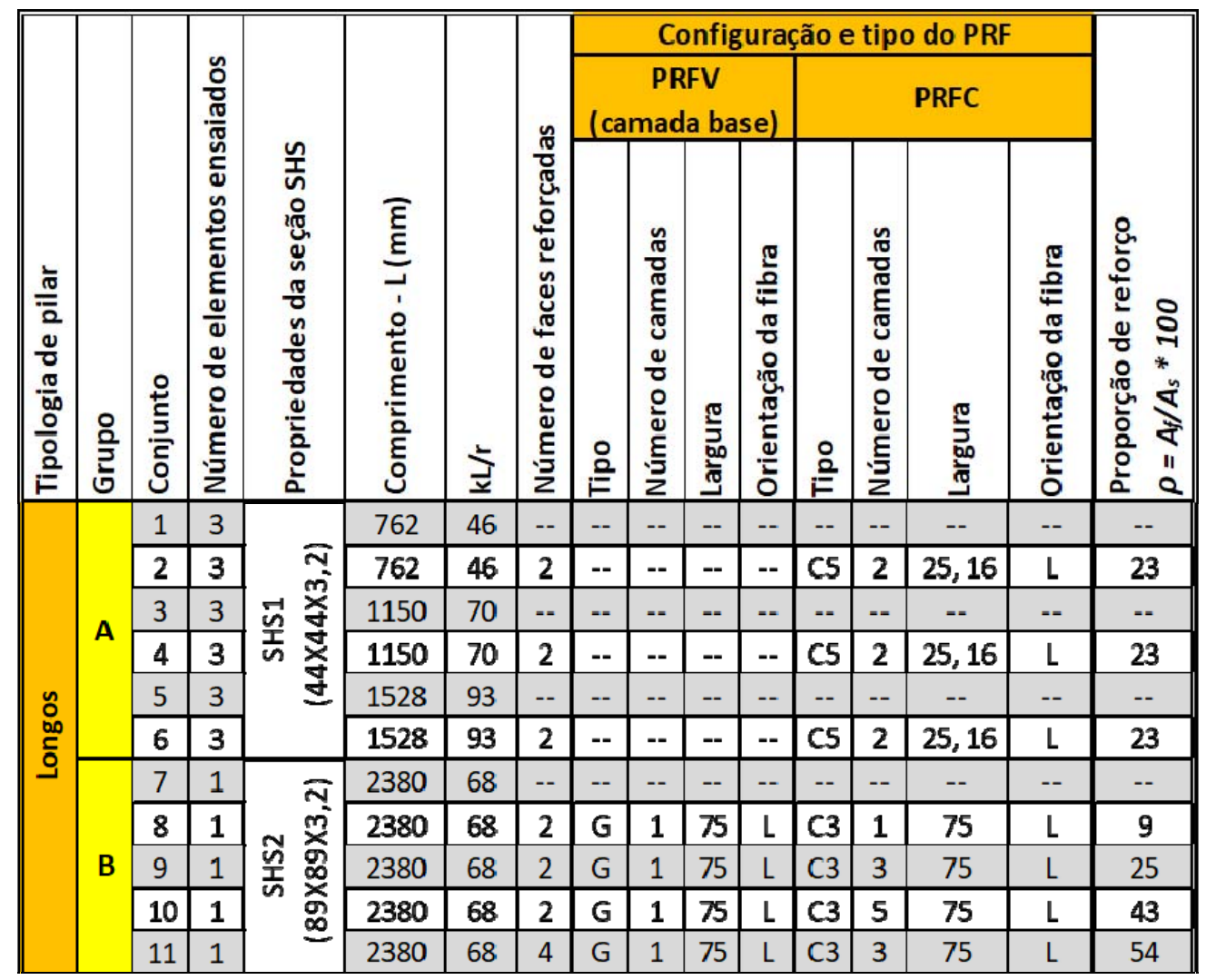

As propriedades geométricas e mecânicas médias, das tipologias dos PRF apresentadas acima, designadas por G para o PRFV e C3 e C5 para o PRFC, são apresentadas na tabela 2.

Tabela 2 - Propriedades mecânicas e geométricas dos PRF (SHAAT 2007).

\begin{tabular}{|c|c|c|c|c|c|c|c|}
\hline & PRF & $\begin{array}{c}\text { Largura - b } \\
(\mathrm{mm})\end{array}$ & $\begin{array}{l}\text { Número de } \\
\text { camadas }\end{array}$ & $\begin{array}{c}\text { Espessura - } t \\
(\mathrm{~mm})\end{array}$ & \begin{tabular}{|c|}
$\begin{array}{c}\text { Módulo de } \\
\text { Elasticidade - E } \\
(\mathrm{GPa})\end{array}$ \\
\end{tabular} & $\begin{array}{c}\text { Tensão } \\
\text { última - } \mathrm{f}_{\mathrm{u}} \\
(\mathrm{MPa})\end{array}$ & $\begin{array}{c}\text { Deformação } \\
\text { última - } \varepsilon_{\mathrm{u}} \\
(\% \circ)\end{array}$ \\
\hline \multirow{2}{*}{ 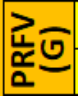 } & Média & 19,27 & \multirow{2}{*}{2} & 3,00 & 17,6 & 336 & 20,0 \\
\hline & Desvio & 0,19 & & 0,08 & 0,8 & 48 & 1,0 \\
\hline \multirow{2}{*}{ 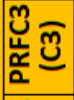 } & Média & 19,40 & \multirow[t]{2}{*}{2} & 1,08 & 230,6 & 510 & 2,2 \\
\hline & Desvio & 0,02 & & 0,05 & 38,6 & 39 & 0,4 \\
\hline \multirow{2}{*}{ 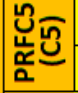 } & Média & 16,43 & \multirow{2}{*}{2} & 3,01 & 313,1 & 1475 & 4,7 \\
\hline & Desvio & 0,07 & & 0,07 & 11,2 & 89 & 0,3 \\
\hline
\end{tabular}


As configurações da disposição do reforço na seção são apresentadas na Figura 8.

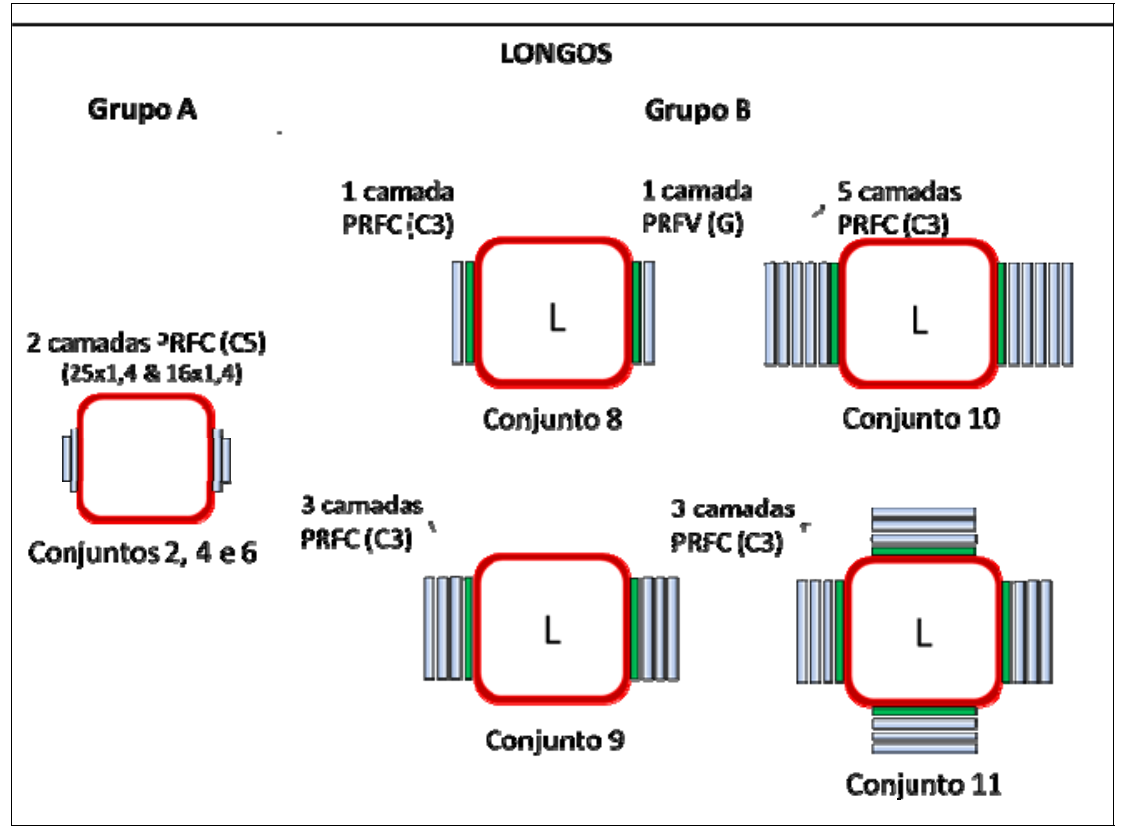

Figura 8 - Configurações de reforço avaliadas.

Os perfis foram produzidos de acordo com a norma canadense CAN/CSA S136-94, classe $\mathrm{C}$ (formados à frio sem alívio de tensões residuais). As propriedades do aço foram aferidas através de ensaios padronizados. A partir destes, foram obtidas as curvas tensão deformação dos aços das seções SHS1 $(44 \times 44 \times 3,2)$ e SHS2 $(89 \times 89 \times 3,2)$, das quais foram obtidas as tensões de proporcionalidade $\left(f_{p}\right)$ e resistência ao escoamento $\left(f_{y}\right)$. Para a seção SHS1 obteve-se $f_{p}$ igual a $257 \mathrm{MPa}$ e $f_{y}$ igual a $504 \mathrm{MPa}$, já para a seção SHS2 obteve-se $f_{p}$ igual a $255 \mathrm{MPa}$ e $\mathrm{f}_{\mathrm{y}}$ igual a $382 \mathrm{MPa}$.

Shaat (2007) estimou a intensidade das tensões residuais $\left(f_{r s}\right)$ como sendo a diferença entre a tensão de escoamento e o limite de proporcionalidade. Desta forma, as seções SHS1 apresentaram tensões residuais com intensidade equivalente a $49 \%$ da tensão de escoamento e as seções SHS2 de 33\%.

Como adesivo, foram utilizadas duas tipologias, o Tyfo $S$, de matriz epóxi, para o grupo B e o Sikadur-30 para o grupo A, também de matriz epóxi.

Para os elementos reforçados, antes da colagem do PRF, os mesmos passaram por um processo de preparação da superfície, através de jateamento de areia, afim de eliminar 
pequenas imperfeições, óxidos e detritos, visando melhorar a aderência entre o aço e 0 adesivo.

Nos corpos de prova, as imperfeições geométricas iniciais foram medidas através de um sensor a laser do tipo ILD1400. Através deste, foram mensuradas as imperfeições dos elementos ao longo do seu comprimento, em duas faces perpendiculares. Para as análises numéricas são utilizadas as imperfeições máximas aferidas, denominadas por $e^{\prime}$, e apresentadas junto as respostas obtidas para cada caso (Figuras 9 a 12).

Todos os pilares foram ensaiados sob compressão centrada. Afim de forçar a ocorrência da instabilidade no plano de reforço, os pilares foram travados em uma direção. Para a simulação de apoios rotulados nas extremidades, foram utilizados roletes.

Além dos resultados experimentais, Shaat (2007) desenvolveu dois modelos de análise, para predizer o comportamento de pilares reforçados. Um deles, denominado modelo de fibra não-linear (modelo 01), consiste em um modelo analítico interativo incremental, baseado no equilíbrio de forças e momentos e compatibilidade de deslocamentos. O outro modelo, foi desenvolvido através do software ANSYS $^{\circledR}$ (modelo 02). Portanto, os resultados obtidos serão também comparados aos resultados dos modelos mencionados, reproduzidos da pesquisa do autor.

Afim de comparação e validação, foram inseridos nos modelos os mesmos parâmetros previamente definidos na campanha experimental, como propriedades dos materiais, geometria, condições de vinculação, carregamento, imperfeições geométricas iniciais e tensões residuais.

Nas Figuras de 9 a 12, serão apresentados os resultados obtidos através da estratégia numérica desenvolvida e estes comparados aos obtidos por Shaat (2007), por meio de curvas do tipo força $x$ deslocamento, para pilares sem reforço, referentes aos ensaios dos conjuntos 1 e 3 do grupo $A$. 


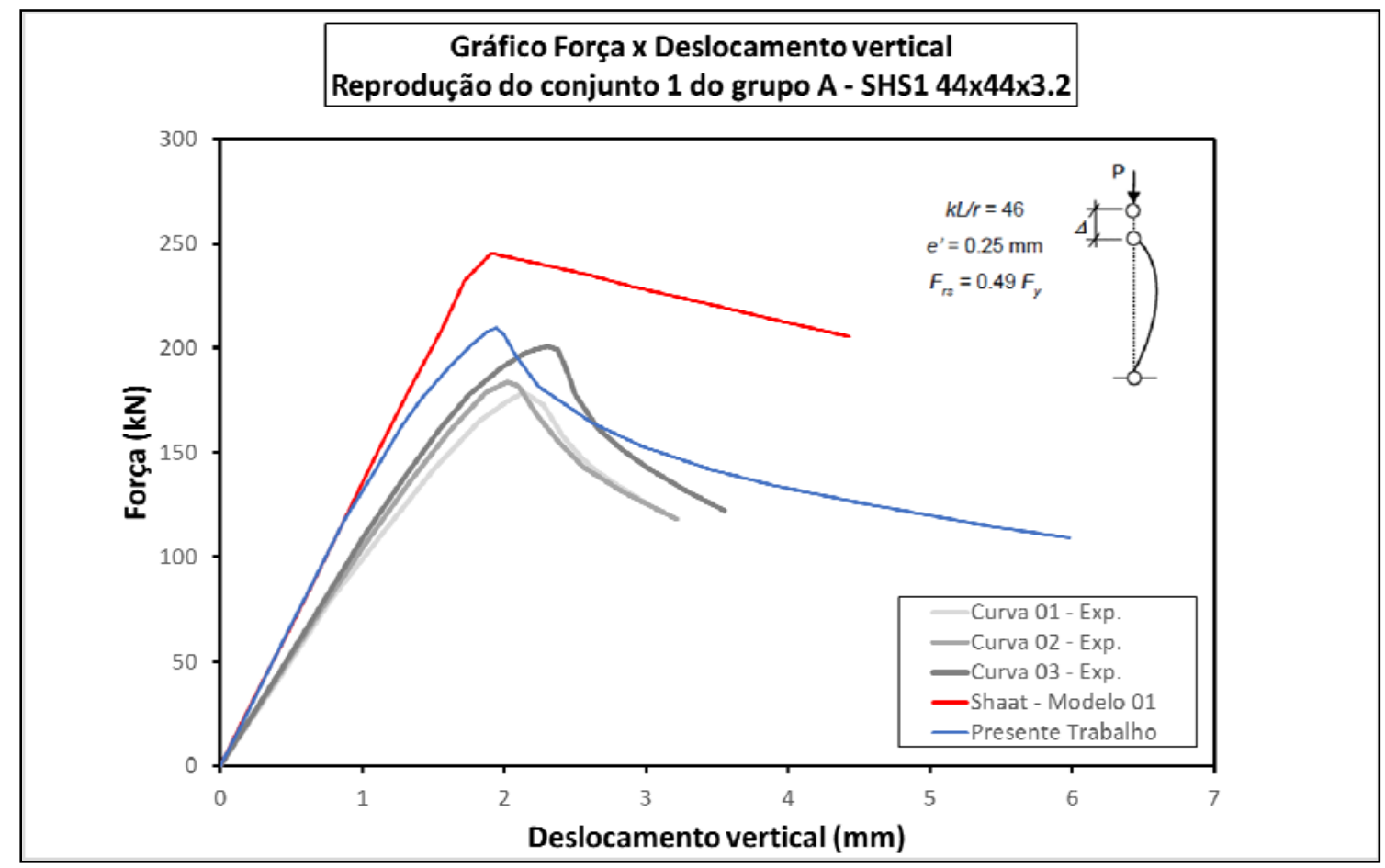

Figura 9 - Curva força $x$ deslocamento vertical do grupo A (conjunto 1).

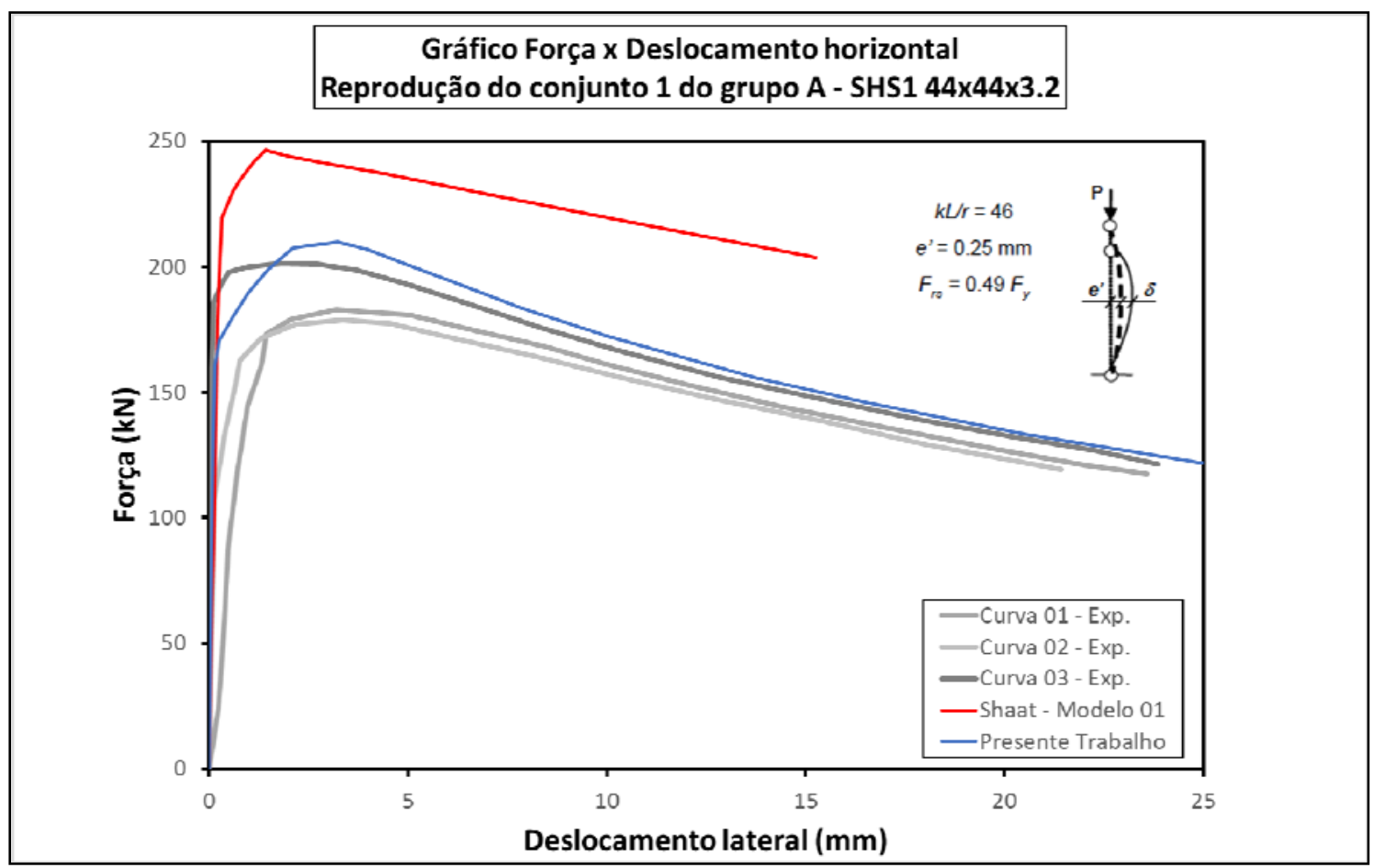

Figura 10 - Curva força $x$ deslocamento horizontal do grupo A (conjunto 1). 


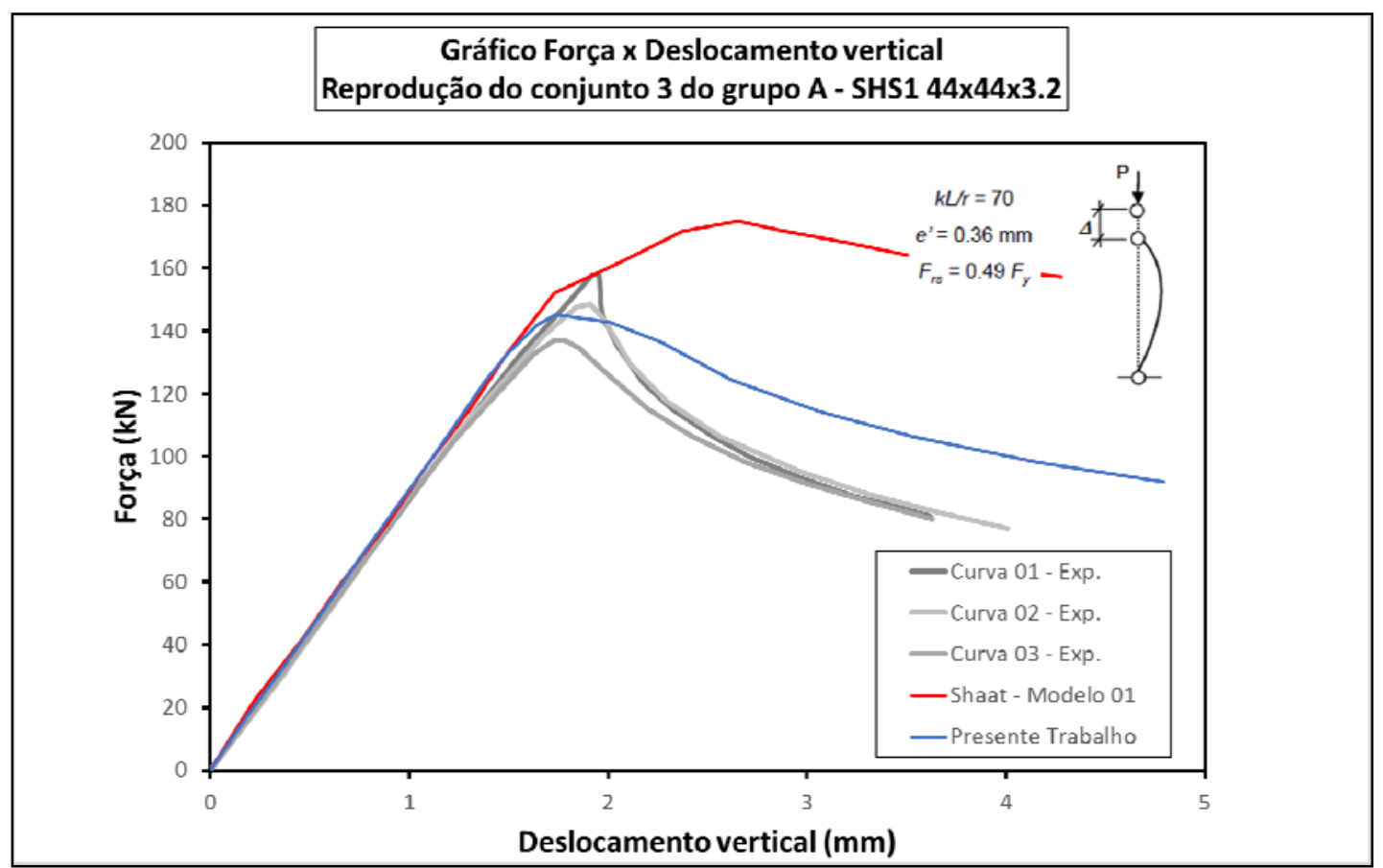

Figura 11 - Curva força $x$ deslocamento vertical do grupo A (conjunto 3).

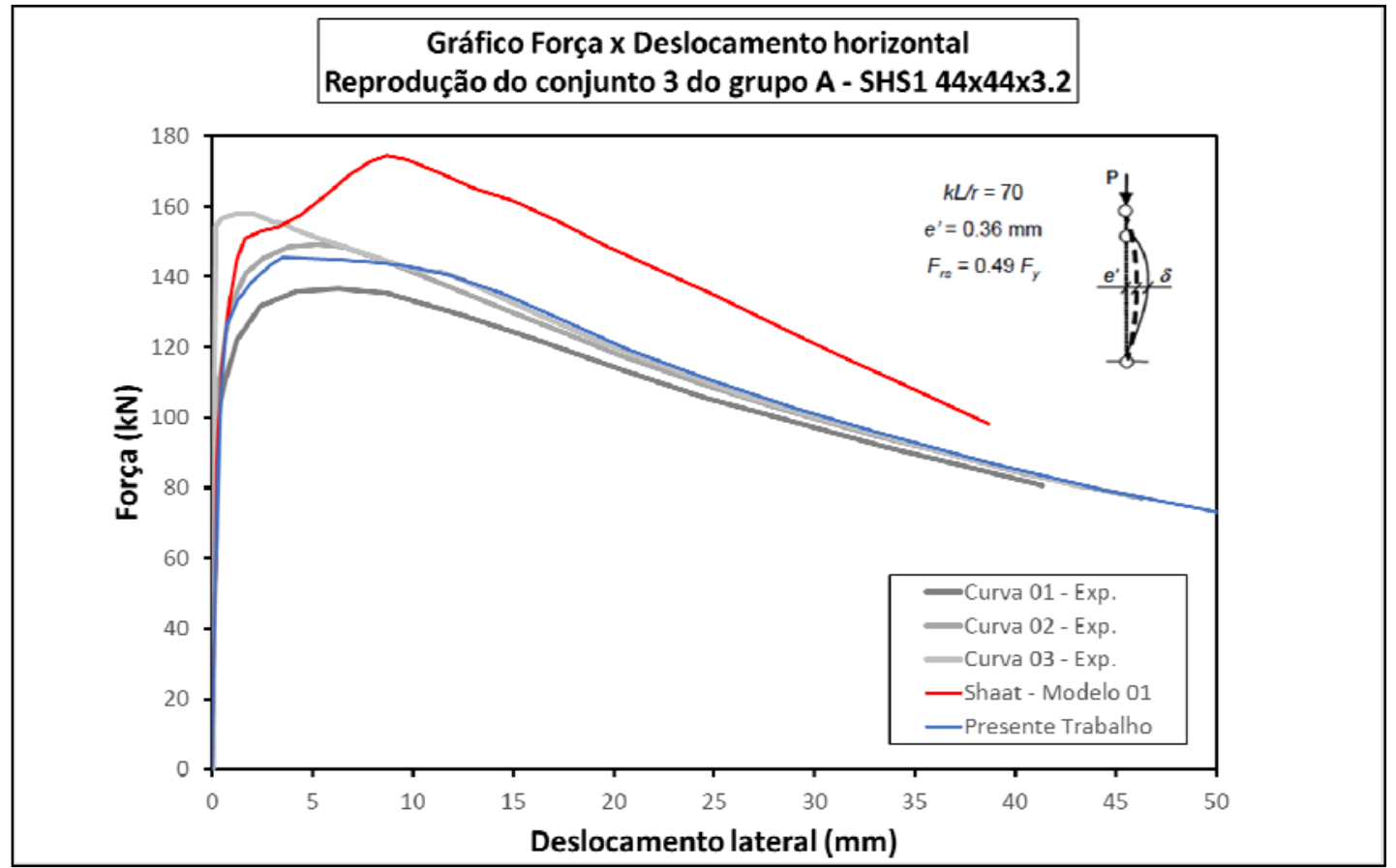

Figura 12 - Curva força $x$ deslocamento horizontal do grupo A (conjunto 3 ).

Por meio de análise das curvas força $\mathrm{x}$ deslocamento nas Figuras de 9 a 12, obtidas através da estratégia numérica apresentada, é possível perceber que os resultados das simulações são compatíveis com os resultados experimentais, tanto do ponto de vista de capacidade última como em termos de rigidez. 
A comparação de resultados obtidos através da estratégia numérica aos experimentais, para pilares reforçados, é apresentado a seguir, nas Figuras 13 a 16, referentes aos ensaios do conjunto 6 do grupo $A$ e 8 do grupo $B$.

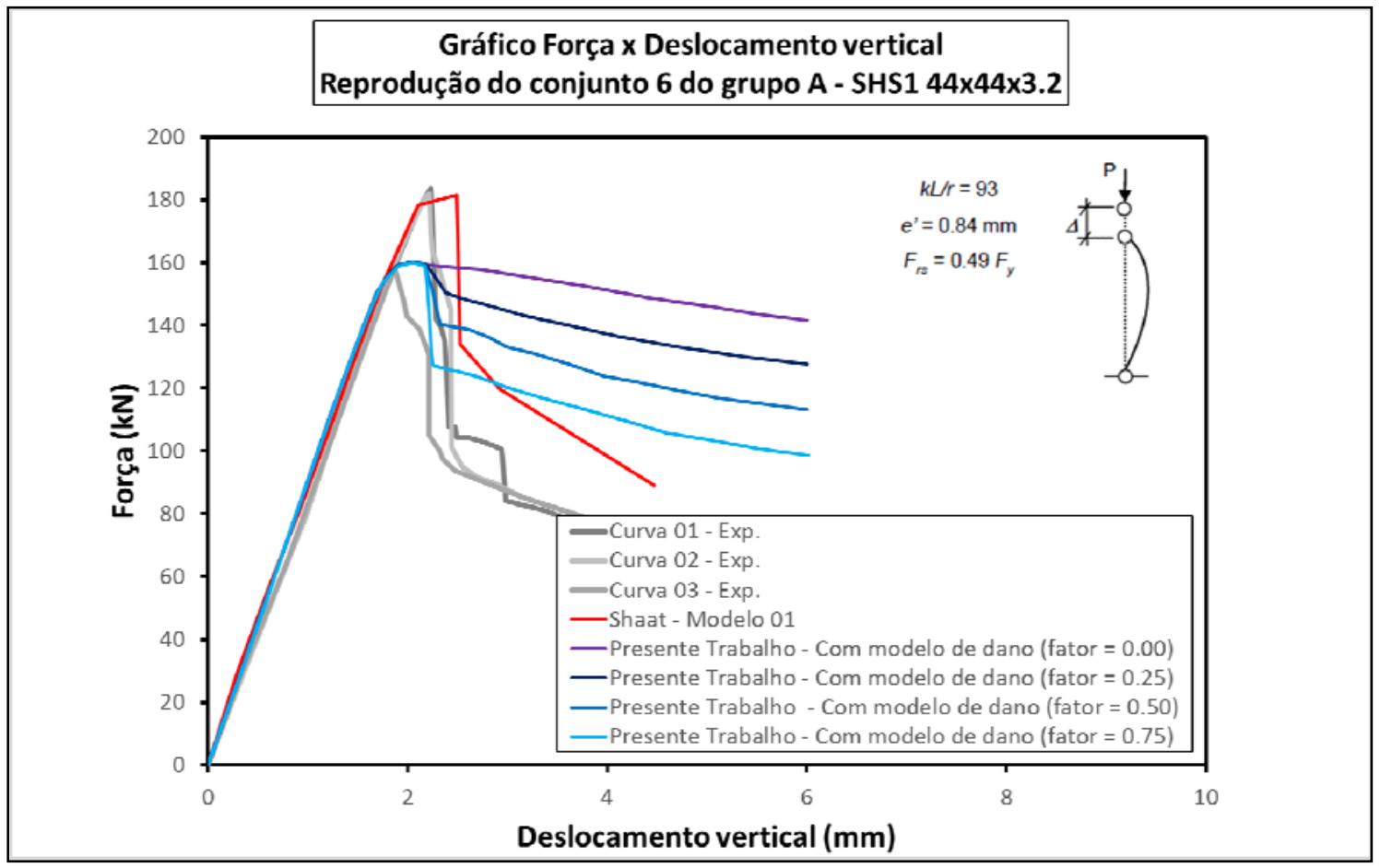

Figura 13 - Curva força $x$ deslocamento vertical do grupo A (conjunto 6).

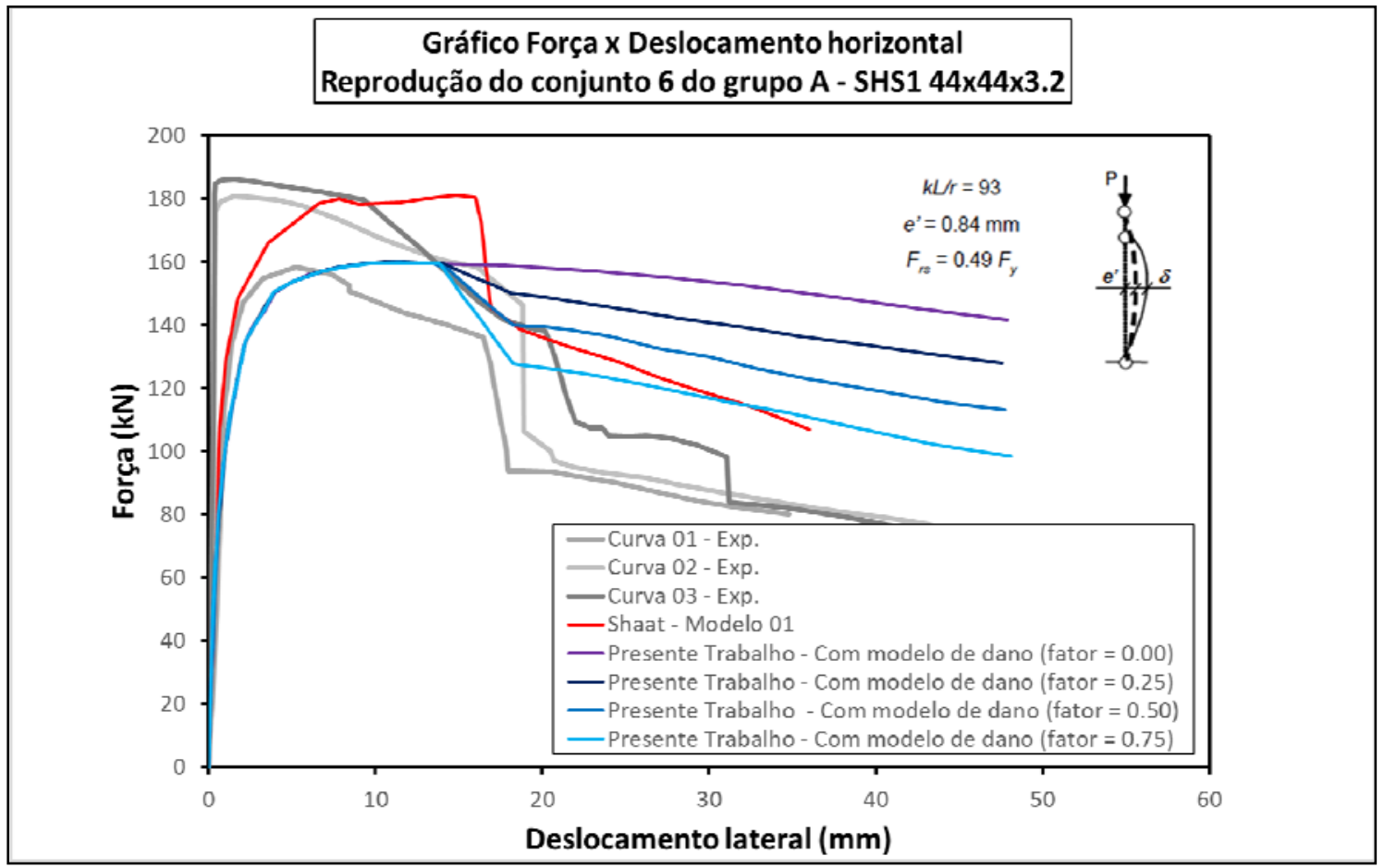

Figura 14 - Curva força $x$ deslocamento horizontal do grupo A (conjunto 6). 


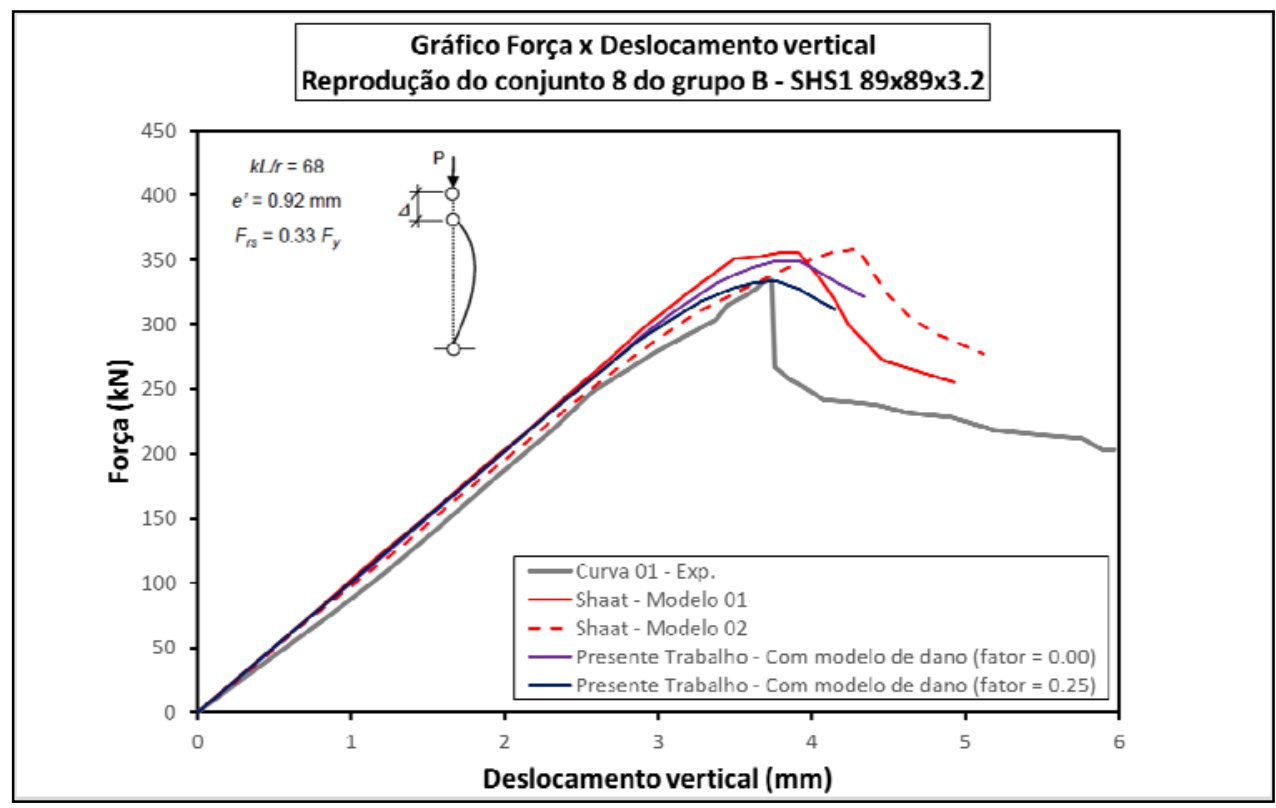

Figura 15 - Curva força $x$ deslocamento vertical do grupo B (conjunto 8).

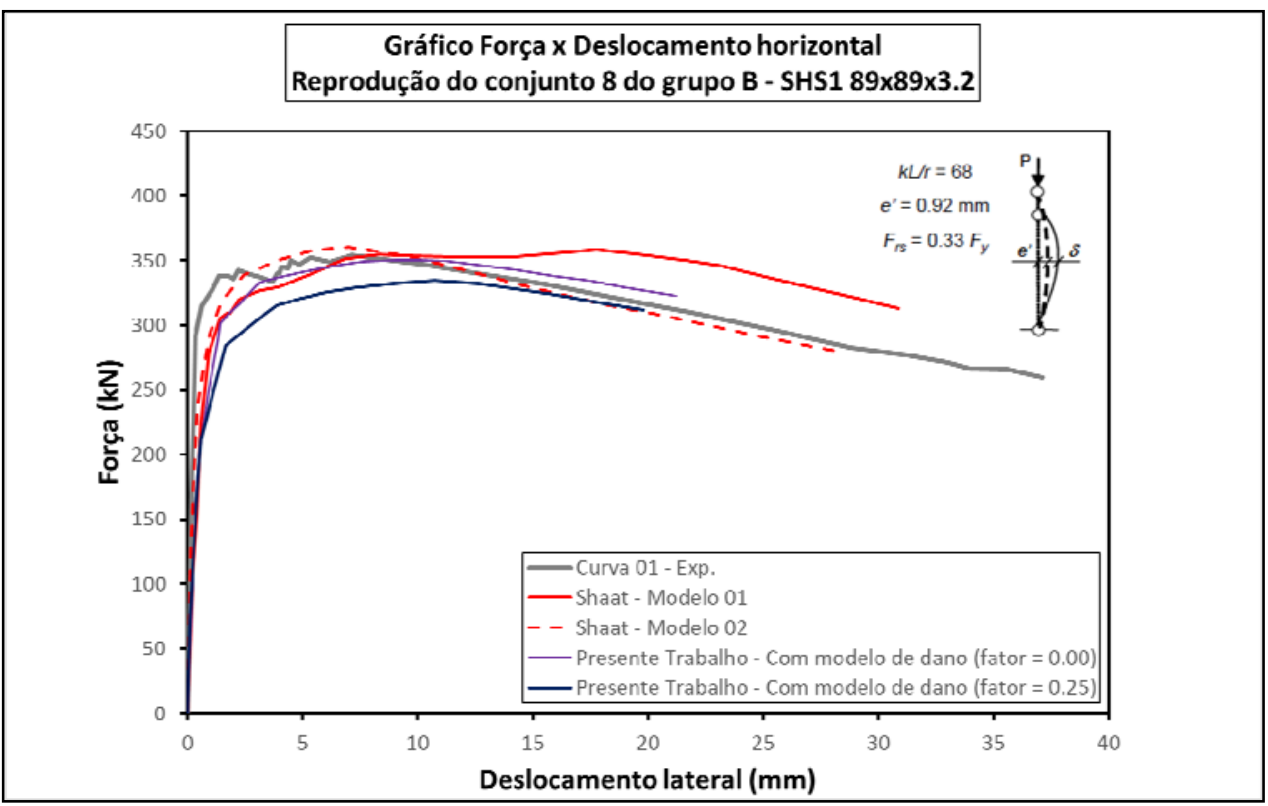

Figura 16 - Curva força $x$ deslocamento horizontal do grupo B (conjunto 8).

Pode-se notar que relação aos resultados das Figuras 13 e 14 que, embora o presente trabalho apresentar resultados mais conservadores do que os resultados de Shaat (2007), tanto em relação ao modelo numérico quanto para duas curvas experimentais, há de se notar que em relação a terceira curva experimental o resultado obtido é muito próximo até o carregamento de colapso. Isso, junto com a excelente aproximação dos resultados obtidos em relação aos resultados experimentais de Shaat (2007) apresentada nas Figuras 15 e 16, significa que em geral, com a utilização de um 
fator de dano igual a 0,25, a estratégia adotada conduz a resultados adequados e no mínimo a favor da segurança. Pode-se notar ainda que o fator de dano se apresenta como um importante parâmetro de avaliação da capacidade resistente do elemento, porém, em termos de rigidez há de se investigar um modelo de dano progressivo para capturar mais adequadamente o comportamento pós-colapso.

\section{Conclusões}

A técnica de reforço de pilares tubulares com PRFC se apresenta como uma técnica viável e promissora, porém ainda com uma baixa aplicação mercadológica, em função do pouco conhecimento e difusão.

O ganho de resistência de pilares tubulares reforçados em relação aos não reforçados, quando submetidos a compressão, é dependente principalmente de fatores como índice de esbeltez global e local, bem como da taxa de reforço empregado. Isso indica a necessidade de maiores estudos e realização de análises paramétricas. Porém, antes de tudo, o desenvolvimento de estratégia de análise numérica adequada é de interesse e foi o objetivo do presente estudo.

Para as situações sem reforço, as respostas numéricas obtidas na presente pesquisa, em termos de rigidez inicial, se aproximaram mais aos resultados teóricos de Shaat (2007), principalmente para o conjunto 1. Em relação à capacidade resistente, para o conjunto 1, a capacidade resistente obtida foi superior à média das curvas experimentais, porém mais próxima aos resultados experimentais que a resposta do modelo analítico de Shaat (2007). Já para conjunto 3, tanto a resistência como a rigidez se apresentaram um pouco menores que aquelas das curvas experimentais.

Nas situações dos elementos com reforço de PRFC, para os conjuntos avaliados, a capacidade resistente se apresentou praticamente equivalente ou um pouco menor à capacidade resistente dos elementos ensaiados experimentalmente, quando se considera um fator de dano igual a 0,25. Em termos de rigidez, o modelo numérico apresentou resultados praticamente iguais aos dos ensaios experimentais até o colapso. De maneira geral, os resultados da estratégia desenvolvida se apresentaram 
mais a favor da segurança e mais próximos aos resultados experimentais que aqueles obtidos em Shaat (2007), tanto por meio de modelo analítico quanto numérico.

Tendo em vistas as análises efetuadas, o fator de dano igual a 0,25 é o mais indicado para obtenção de resultados para fins práticos com a estratégia numérica apresentada.

Para o caso de pilares tubulares de aço longos, de seção quadrada, reforçados ou não, a estratégia numérica desenvolvida se apresentou como uma solução viável e eficiente para a previsão do comportamento quando solicitado à compressão centrada.

\section{Referências bibliográficas}

ANSYS, Inc. ANSYS ${ }^{\circledR}$ Academic Research Mechanical, Release 18.1. Help System, Mechanical APDL Documentation, 2017.

CANADIAN STANDARDS ASSOCIATION. Cold formed steel structural members. CAN/CSA-S136-94. Rexdale. Ontário, 1994.

CHODRAIU, G. M. B. Análise teórica e experimental de perfis de aço formados a frio submetidos à compressão. Tese de doutorado. São Carlos. São Paulo. Universidade de São Paulo. Escola de Engenharia de São Carlos, 2006.

DEVI, U. Finite element investigation on the capacity of slender HSS steel columns strengthened with multilayer CFRP strips. Dhaka, Bangladesh: Department of Civil Engineering. Bangladesh University of Engineering and Technology (BUET), 2016.

LANE, I. R.; WARD J. A. Restoring Briatin's bridge heritage. Institution of Civil Engineers (South Wales Association). Transport Engineering Group Award, 2000.

PEREIRA, D. H. F. Análise do comportamento estrutural de ligações de aço entre viga de seção I e pilar de serção tubular circular. Dissertação de mestrado. São Carlos. São Paulo. Universidade de São Paulo. Escola de Engenharia de São Carlos, 2013.

SHAAT, A. Strctural behavior of steel columns and steel-concrete composite girders retrofitted using CFRP. Tese de doutorado. Kingston. Ontario. Canada. Queen's University, 2007.

SHAAT, A.; FAM, A. Axial loading tests on CFRP-retrofitted short and long. Canadian Journal of Civil Engineering. pp. 458-70, 2006.

TAWFIK, Q. H.; KARUNASENA, W. Use of CFRP for Rehabilitation of Steel Structures: a Review. Southern Region Engineering Conference. Toowoomba, QLD, Australia, 2010.

ZHAO, X. L.; ZHANG. L. State-of-the-art review on FRP strengthened steel structures. pp. 29 (8), 1808-1823, 2007.

ZHAO, X. L. FPR-Strengthened - Metallic Structures. Boca Raton, Flórida, EUA. Taylor \& Francis Group, 2014. 